\title{
Características de carcaça e análise do custo de sistemas de produção de cordeiras $1 / 2$ Dorset Santa Inês
}

\author{
Graziela Aparecida Santello1, Francisco de Assis Fonseca de Macedo², Alexandre Agostinho \\ Mexia $^{2}$, Eduardo Shiguero Sakaguti ${ }^{2}$, Fábio Jacobs Dias ${ }^{1}$, Marcelo Farid Pereira ${ }^{3}$
}

${ }^{1}$ Doutorando da Universidade Estadual de Maringá - Av. Colombo, cep: 87020-900 - Maringá, PR.

${ }^{2}$ Curso de Zootecnia Universidade Estadual de Maringá - Av. Colombo, cep: 87020-900 - Maringá, PR.

${ }^{3}$ Curso de Economia da Universidade Estadual de Maringá - Av. Colombo, cep: 87020-900 - Maringá, PR.

RESUMO - Um experimento foi realizado com os objetivos de avaliar as características de carcaça de cordeiras $1 / 2$ Dorset Santa Inês e comparar o custo de produção e o retorno econômico de dois sistemas de terminação. Após o desmame, 44 cordeiras foram divididas em dois sistemas de terminação: confinamento - ração (4\% PV) com 15,56\% de PB e 4,32 Mcal de EB/kg MS; e pastagem + suplementação (1,5\% de ração, com base no peso vivo), com 27,01\% PB e 4,51 Mcal de EB/kg MS. Os custos da ração e do suplemento foram de $\mathrm{R} \$ 0,39$ e $\mathrm{R} \$ 0,54$, respectivamente. Os animais foram abatidos ao atingirem peso corporal médio de $30 \mathrm{~kg}$. Os valores médios para os pesos da carcaça quente e fria foram de 14,33 e 14,11 kg e 13,91 e 13,6 kg, os rendimentos verdadeiros médios de 55,81 e $55,61 \%$ e os comerciais de 46,39 e $46,04 \%$, respectivamente, para confinamento e pastagem + suplementação. As médias para condição corporal e índices de compacidade da carcaça e da perna das cordeiras terminadas em confinamento e pastagem + suplementação foram, respectivamente, de 3,03 e 2,96; 0,21 e $0,20 \mathrm{~kg} / \mathrm{cm}$ e 0,43 e $0,44 \mathrm{~cm} / \mathrm{cm}$. As características idade ao abate, condição corporal, pesos da carcaça quente e fria, rendimentos verdadeiro e comercial da carcaça e índices de compacidade da carcaça e da perna não diferiram entre os tratamentos. Portanto, cordeiras $1 / 2$ Dorset Santa Inês podem ser terminadas em confinamento ou em pastagem + suplementação, porém, considerando-se a análise econômica, recomenda-se a terminação em pastagem + suplementação.

Palavras-chave: carne de cordeiro, custo de produção, qualidade de carcaça, retorno econômico

\section{Carcass characteristics and production costs of $1 / 2$ Dorset Santa Inês lambs finished at two different systems}

\begin{abstract}
The objectives of this trial were to evaluate carcass characteristics and production costs of $1 / 2$ Dorset Santa Inês lambs finished at two finishing systems. Forty-four weaned $1 / 2$ Dorset Santa Inês lambs were distributed to one of the following two finishing systems: 1) feedlot lambs were fed concentrate $(4 \% \mathrm{BW})$ containing $15.56 \% \mathrm{CP}$ and $4.32 \mathrm{Mcal}$ $\mathrm{GE} / \mathrm{kg} \mathrm{DM}$ or 2) lambs were on pasture and received a supplement (1.5\% BW) containing 27.01\% CP and $4.51 \mathrm{Mcal} \mathrm{GE} / \mathrm{kg}$ DM. Concentrate and supplement costs were R\$ 0.39 and R $\$ 0.54$, respectively. Animals were slaughtered when they reached, on average, $30 \mathrm{~kg}$ of BW. Mean values for hot and cold carcass weights were 14.33 and $14.11 \mathrm{~kg}$ and 13.91 and $13.6 \mathrm{~kg}$ for animals on feedlot and pasture plus supplementation system, respectively. Carcass and commercial carcass yields were 55.81 and $55.61 \%$ and 46.39 and $46.04 \%$ for animals on feedlot and pasture plus supplementation system, respectively. It was also observed, in this order, the following mean values for body condition score, and carcass and hindlimb compactness indexes: 3.03 and $2.96 ; 0.21$ and $0.20 \mathrm{~kg} / \mathrm{cm} ; 0.43$ and $0.44 \mathrm{~cm} / \mathrm{cm}$ for animals on feedlot and pasture plus supplementation system, respectively. Slaughter age, body condition score, hot and cold carcass weights, carcass and commercial carcass yields, carcass and hindlimb compactness indexes all did not differ between treatments indicating that lambs can be finished either at feedlot or at pasture plus supplementation. However, according to the economical analysis is recommended the pasture plus supplementation finishing system.
\end{abstract}

Key Words: economical income, lamb meat, meat quality, production cost

\section{Introdução}

O rápido ciclo produtivo de dez meses (cinco de gestação e cinco para cria e recria) faz da ovinocultura uma das atividades pecuárias com retorno econômico garantido em países como Nova Zelândia, Austrália, Uruguai e outros da Europa. Raças nacionais como Santa Inês tem apresentado considerável aumento nas regiões Sudeste e Centro-Oeste 
do Brasil, em virtude de sua elevada rusticidade, alta prolificidade, menor susceptibilidade aos parasitos e maior eficiência reprodutiva, apresentando cios durante todo o ano (Bueno et al., 2000), o que sugere sua utilização como raça materna visando à produção de cordeiros para abate.

Em sistemas intensivos, cordeiros Santa Inês têm desempenho e características de carcaças inferiores às raças de corte, todavia, a utilização de reprodutores destas raças sobre ovelhas Santa Inês pode melhorar estas características, produzindo crias com maior potencial para ganho de peso e diminuindo o tempo para o abate e o custo de produção (Cunha et al., 2001).

A raça Dorset apresenta comportamento reprodutivo semelhante ao da Santa Inês, com cio durante todo o ano, além de descendentes com bons rendimentos de carcaça. Portanto, cordeiros desta raça podem ser utilizados em cruzamentos com rebanhos maternos comerciais Santa Inês.

O rendimento de carcaça é um parâmetro importante na avaliação dos animais, pois está diretamente relacionado à comercialização de cordeiros e, geralmente, é um dos primeiros índices a ser considerado, por expressar a relação percentual entre o peso da carcaça e o peso corporal do animal. O rendimento de carcaça pode variar conforme a raça, o peso ao abate, os sistemas de alimentação e a idade do animal (Souza, 1993).

A conformação da carcaça, de acordo com Osório (1992), determina indiretamente a quantidade de carne, indicando principalmente o desenvolvimento muscular, enquanto o peso da carcaça representa a totalidade dos tecidos que a compõem. Uma conformação adequada indica desenvolvimento proporcional das diferentes regiões anatômicas que integram a carcaça e as melhores são alcançadas quando as partes de maior valor comercial estão bem pronunciadas (Oliveira et al., 2002). Os índices de compacidade da carcaça e da perna, por sua vez, representam a relação das massas muscular e adiposa com o comprimento e serve para avaliação da quantidade de tecido depositado por unidade de comprimento, sendo uma avaliação objetiva da conformação (Cunha et al., 2002).

Para que a produção ovina seja técnica e economicamente viável, é necessário, entre outros fatores, proporcionar ao animal condições para máximo desempenho de suas potencialidades por meio do fornecimento de alimentação adequada, visando alcançar as condições de peso e/ou terminação para abate mais precocemente.

Os objetivos neste trabalho foram avaliar as características de carcaça de cordeiras $1 / 2$ Dorset Santa Inês terminadas em confinamento ou em pastagem + suplementação e comparar o custo de produção e o retorno econômico desses dois sistemas de terminação.

\section{Material e Métodos}

O experimento foi realizado no Centro de Pesquisa do Arenito, da Universidade de Maringá, no município de Cidade Gaúcha, Noroeste do Paraná. Foram utilizadas 44 cordeiras $1 / 2$ Dorset Santa Inês, originadas de parto simples ou duplo, filhas de 31 ovelhas Santa Inês com peso médio de $45,11 \mathrm{~kg}$ e três cordeiros da raça Dorset.

Da cobertura à parição, as ovelhas permaneceram, no período noturno, em área estabelecida de capim-tanzânia (Panicum maximum Jacq. cv. Tanzânia) e, no período diurno, foram recolhidas em instalações cobertas, com piso ripado e suspenso, onde recebiam resíduo de fécula de mandioca no cocho na proporção de $2 \mathrm{~kg} / \mathrm{animal} /$ dia.

Foram avaliados quatro tratamentos: no tratamento controle, os animais permaneceram em pastagem de capim-tanzânia suplementada com resíduo de mandioca e, nos outros três, houve suplementação alimentar diferenciada conforme a fase de gestação: terço inicial (TI) - pastagem e resíduo de mandioca + suplementação do $1^{\circ}$ ao $50^{\circ}$ dia de gestação; terço médio (TM) - pastagem e resíduo de fécula de mandioca + suplementação do $50^{\circ}$ ao $100^{\circ}$ dia de gestação; e terço final (TF) - pastagem e resíduo de fécula de mandioca + suplementação do $100^{\circ}$ dia de gestação até parição.

O suplemento foi calculado para atender às exigências nutricionais das ovelhas nas diferentes fases de gestação (NRC, 1985), sendo fornecido somente no período da manhã, antes de os animais serem levados para a pastagem, nas quantidades de $0,400 \mathrm{~kg} / \mathrm{dia}$ (dois primeiros terços da gestação) e de $0,600 \mathrm{~kg} /$ dia (terço final). A composição química do suplemento nos dois primeiros terços da gestação foi de $18,11 \%$ PB e 4,04 Mcal de EB/kg na MS e, no terço final, de $24,03 \% \mathrm{~PB}$ e $4,05 \mathrm{Mcal}$ de EB/ $\mathrm{kg}$ na MS.

As cordeiras foram vacinadas contra éctima contagioso aos 15 dias de idade e, aos 45 dias, receberam vacina contra carbúnculo, gangrena gasosa e enterotoxemia. $\mathrm{Na}$ primeira semana de vida, as ovelhas e as cordeiras ficaram alojadas nas instalações; na $2^{\mathrm{a}}$ e $3^{\mathrm{a}}$ semanas, somente as ovelhas foram soltas por 4 horas nos piquetes e, da $4^{\text {a }}$ semana até o desmame, somente as ovelhas foram soltaspor 8 horas nos piquetes. Todas as cordeiras, do nascimento até a entrada no sistema de terminação, receberam o mesmo manejo, com acesso ao creep feeding, recebendo dieta formulada para ganho de peso médio de $230 \mathrm{~g} /$ dia (NRC, 1985). A ração (20\% de PB, 3,0 Mcal de $\mathrm{EB} / \mathrm{kg}$ na MS, $1,46 \%$ de Ca e 1,0\% de P) foi constituída de $55 \%$ de grão de milho, $24 \%$ de farelo de soja, $9 \%$ de farelo de trigo $10 \%$ de feno de aveia, $2 \%$ de mistura mineral comercial, $0,2 \%$ lisina e $0,08 \%$ de metionina. A idade de 
entrada dos animais no sistema de terminação variou de 60 a 75 dias de idade $(20,58 \mathrm{~kg} \pm 0,39$ de PV).

O suplemento e a ração do confinamento foram formulados para atender às exigências nutricionais das cordeiras e proporcionar ganhos médios de $0,200 \mathrm{~kg} / \mathrm{dia}(\mathrm{NRC}, 1985)$. Os animais foram alocados em dois tratamentos, conforme a origem do tratamento de suas mães e o tipo de parto (simples ou duplo): OS - pastagem de coastcross (Cynodon dactylon L. Pers) durante o dia + suplementação na instalação; CT - confinamento total com ração completa.

No tratamento OS, 21 cordeiras, nove de parto simples e 12 de parto gemelar, foram mantidas nas instalações cobertas (piso ripado e suspenso) no período noturno, sendo soltas às $9 \mathrm{~h}$ em pastagem de coastcross e recolhidas nas instalações por volta das $16 \mathrm{~h} 30$, onde receberam suplemento (Tabela 1). Para obtenção da composição química da coastcross, foram recolhidas amostras pelo método de dupla amostragem (Wilm et al., 1944).

Para o tratamento CT, foram utilizadas 23 cordeiras, nove de nascimento simples e 14 de nascimento gemelar, alojadas em baias coletivas cobertas (piso ripado e suspenso), onde recebiam água à vontade e ração completa (Tabela 1). A ração do confinamento foi fornecida duas vezes ao dia, totalizando, em média 4,0\% do PV. A proporção volumoso:concentrado foi de 30:70.

Todas as cordeiras foram pesadas no início do experimento e a cada 14 dias, com a finalidade de monitorar seu desenvolvimento.

Em ambos os tratamentos, as cordeiras tinham acesso a sal mineral na proporção $12 \mathrm{~g} / \mathrm{animal} / \mathrm{dia}$, fornecido nas instalações. O custo do quilo da ração do confinamento foi de $R \$ 0,39$ e, para o sistema de pastagem, o quilo do suplemento foi de $\mathrm{R} \$ 0,54$.

A infecção por endoparasitos foi acompanhada pela contagem de ovos por grama de fezes (OPG), sendo as cordeiras everminadas nos casos de contagens superiores a $500 \mathrm{OPG}$

Ao atingirem $30,0 \mathrm{~kg}$ de peso corporal, as cordeiras foram submetidas a dieta hídrica por 18 horas, sendo abatidas em seguida por meio de insensibilização (descarga elétrica de $220 \mathrm{~V}$ por 8 segundos) e secção das veias jugulares e das artérias carótidas.

No momento do abate, determinou-se a condição corporal (CC). O método de avaliação da CC em ovinos foi desenvolvido na Inglaterra por Russel et al. (1969) e baseia-se na palpação da região dorsal da coluna vertebral, verificando-se a quantidade de gordura e músculo encontrada no ângulo formado pelos processos dorsais e transversos. Dessa forma, são atribuídos valores de 1 a 5 , em que 1 representa animal caquético e 5 , animal obeso.
Tabela 1 - Composição das dietas experimentais (\% MS) Table 1 - Ingredient composition of the experimental diets (\% DM)

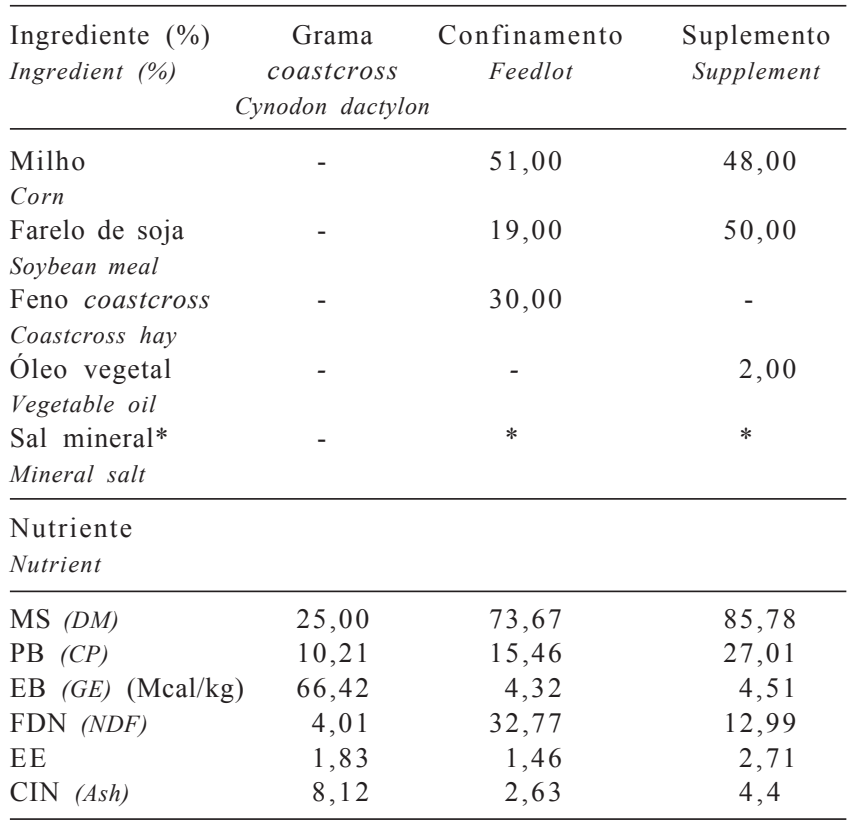

* Formulação comercial (Product composition): Ca - $120 \mathrm{~g}, \mathrm{Na}-147 \mathrm{~g}, \mathrm{~S}$ $18 \mathrm{~g}, \mathrm{Cu}-590 \mathrm{mg}, \mathrm{Co}-40 \mathrm{mg}, \mathrm{Cr}-20 \mathrm{mg}, \mathrm{Fe}-1.800 \mathrm{mg}, \mathrm{I}-80 \mathrm{mg}$ $\mathrm{Mg}-1.300 \mathrm{mg}, \mathrm{Se}-15 \mathrm{~g}, \mathrm{Zn}-3.800 \mathrm{mg}$

Ao abate, os animais foram novamente pesados (peso vivo ao abate). Em seguida, o aparelho gastrintestinal foi esvaziado para obtenção do peso corporal vazio (peso vivo ao abate subtraído do peso do conteúdo gastrintestinal), visando determinar o rendimento verdadeiro e a relação entre o peso da carcaça quente e o peso corporal vazio (Sañudo \& Sierra, 1986).

Terminada a evisceração, as carcaças foram novamente pesadas (peso da carcaça quente), mantidas durante duas horas em temperatura ambiente e posteriormente transferidas para câmara frigorífica a $4^{\circ} \mathrm{C}$, onde permaneceram por 24 horas penduradas pelos tendões em ganchos apropriados, para manutenção das articulações tarsometatarsianas distanciadas a $17 \mathrm{~cm}$.

Após este período, as carcaças (resfriadas) foram novamente pesadas e o rendimento comercial foi calculado (relação peso da carcaça fria $\times$ peso vivo ao abate). Foram realizadas as seguintes mensurações (Sañudo \& Sierra, 1986) para o cálculo dos índices de compacidade:

- comprimento da perna: distância entre o períneo e o bordo anterior da superfície articular tarsometatarsiana;

- comprimento interno da carcaça: distância máxima (tomada com fita métrica) entre o bordo anterior da sínfise ísquio-pubiana e o bordo anterior da primeira costela em seu ponto médio;

- largura da garupa: largura máxima (tomada com compasso e medida com fita métrica) entre os trocânteres de ambos os fêmures. 
Foram então, calculados os índices de compacidade da carcaça (peso da carcaça fria dividido pelo comprimento interno da carcaça) e da perna (largura da garupa dividida pelo comprimento da perna).

Para efetuar a análise do custo operacional do experimento, foram considerados o preço de mercado dos ingredientes da ração de confinamento e do suplemento (farelo de soja, grão de milho, feno e óleo vegetal) e o valor pago na região pela carcaça de cordeiros. Para o sistema de terminação em pastagem, foi atribuído o custo com o arrendamento da pastagem, referente ao valor pago na região com o arrendamento para plantio de cana-de-açúcar. Os consumos de ração e suplemento pelas cordeiras foram calculados pelo consumo de 4 e $1,5 \%$, respectivamente, pelo número de animais e pelos dias em terminação, por meio de pesagem dos animais a cada 14 dias.

A planilha de cálculo foi montada com dados coletados no experimento, referentes a 23 fêmeas terminadas em confinamento e 21 fêmeas em pastagem + suplementação. Entretanto, para que os resultados pudessem ser comparados, considerou-se módulo de 100 cordeiras para cada sistema de terminação.

Os dados do peso vivo ao abate (PVA), pesos de carcaça quente (PCQ) e carcaça fria (PCF), rendimento verdadeiro (RV) e comercial (RC), condição corporal (CC), índices de compacidade da perna (ICP) e da carcaça (ICC) e idade ao abate (IA) foram analisados pelo programa computacional SAS (1992), segundo procedimento GLM, adotando-se o seguinte modelo:

$$
\begin{gathered}
\mathrm{Y}_{i j k l}=\mu+\mathrm{TM}_{i}+\mathrm{TT}_{j}+\mathrm{TP}_{k}+\mathrm{TMxTT}_{i j}+\mathrm{TMxTP}_{i k}+ \\
\mathrm{TTxTP}_{\mathrm{jk}}+\mathrm{b}(\mathrm{PI}-\mathrm{MPI})+\mathrm{e}_{i j k l},
\end{gathered}
$$

em que: $\mathrm{Y}_{i j k l}=$ observação referente ao animal $l$, nascido de parto $k$, acabado no sistema de terminação $j$, cuja ovelha recebeu na gestação a suplementação $i ; \mu=$ constante geral; $\mathrm{TM}_{i}=$ efeito do tipo de suplementação $i$ na gestação; sendo $i=1,2,3$ e $4 ; \mathrm{TT}_{j}=$ efeito do tipo de terminação $j$, sendo $j=1$ e $2 ; \mathrm{TP}_{k}=$ efeito do tipo de parto $k$; sendo $k=1$ e 2 ; $\mathrm{TMxTT}_{i j}=$ efeito da interação tratamento materno x tratamento de terminação; $\mathrm{TMxTP}_{i k}=$ efeito da interação tratamento materno $\times$ tipo de parto; $\mathrm{TTxTP}_{\mathrm{jk}}=$ efeito da interação terminação $\times$ tipo de parto; $\mathrm{b} 1=$ coeficiente de regressão linear da variável em função do peso inicial do cordeiro; $\mathrm{PI}=$ peso inicial do cordeiro na terminação; $\mathrm{MPI}=$ média dos pesos iniciais dos cordeiros; $\mathrm{e}_{i j k l}=$ erro aleatório associado a cada observação $\mathrm{Y}_{i j k l}$.

\section{Resultados e Discussão}

Como não houve efeito da suplementação das ovelhas nas diferentes fases da gestação, do tipo de parto e da interação dessas variáveis sobre as características das carcaças estudadas, considerou-se apenas o efeito de terminação, conforme descrito nas Tabelas 2 e 3 .

Os valores médios de PCQ e PCF obtidos neste experimento foram superiores aos encontrados por Santos et al. (2002), de 13,50 kg para PCQ e 13,00 kg para PCF, em cordeiros Santa Inês puros e cruzados com raças especializadas para corte (Suffolk, Ile de France e Poll Dorset) abatidos com pesos semelhantes. Em pesquisa realizada por Yamamoto et al. (2005) com cordeiros Santa Inês puros e $1 / 2$ Dorset Santa Inês terminados em confinamento e alimentados com ração com diferentes fontes de óleo vegetal, os animais foram abatidos com $30 \mathrm{~kg}$ de peso vivo e apresentaram PCQ e PCF de 14,56 e 14,18 kg para Santa Inês e 14,45 e 14,14 kg para 1/2 Dorset Santa Inês, respectivamente. Os animais abatidos neste experimento foram provenientes de um dos cruzamentos utilizados por esta autora e, portanto, os resultados encontrados foram semelhantes. Diferenças significativas entre os tratamentos podem ter ocorrido principalmente pelo fato de os animais terem a mesma procedência genética e serem mantidos sob dietas com níveis similares de proteína e energia, pois o suplemento foi calculado para suprir a deficiência destes nutrientes na pastagem.

Resultados inferiores para PCF foram obtidos por Macedo et al. (2000), em estudo com cordeiros puros Corriedale (C), mestiços Corriedale x Bergamácia (BC) e Corriedale x Hampshire Down (HC) terminados em confinamento e em pastagem de coastcross $(11,45 \mathrm{e} 12,92 \mathrm{~kg}$,

Tabela 2 - Médias e erros-padrão para peso vivo ao abate (PVA), pesos de carcaça quente (PCQ) e de carcaça fria (PCF) e rendimentos verdadeiro (RVC) e comercial da carcaça (RCC) de cordeiras $1 / 2$ Dorset Santa Inês terminadas em confinamento ou em pastagem + suplementação

Table 2 - Means and standard errors for slaughter weight (SW), hot carcass weight $(\mathrm{HCW})$, cold carcass weight (CCW), carcass yield (CY) and commercial carcass yield (CCY) of $1 / 2$ Dorset Santa Inês lambs finished at feedlot or at pasture

\begin{tabular}{|c|c|c|c|}
\hline \multirow[t]{2}{*}{$\begin{array}{l}\text { Item } \\
\text { Item }\end{array}$} & \multicolumn{3}{|c|}{$\begin{array}{c}\text { Sistema de terminação } \\
\text { Feeding system }\end{array}$} \\
\hline & $\begin{array}{c}\text { Confinamento } \\
\text { Feedlot }\end{array}$ & $\begin{array}{c}\text { Pastagem }+ \\
\text { suplementação } \\
\text { sture plus supplement }\end{array}$ & $\begin{array}{l}\text { Média geral } \\
\text { Overall mean }\end{array}$ \\
\hline PVA $(S W)$ & $29,96 \pm 0,45$ & $29,68 \pm 0,42$ & $29,83 \pm 0,64$ \\
\hline PCQ ( $\mathrm{HCW})$ & $14,33 \pm 0,25$ & $14,11 \pm 0,24$ & $14,23 \pm 0,64$ \\
\hline $\mathrm{PCF}(\mathrm{CCW})$ & $13,91 \pm 0,25$ & $13,67 \pm 0,23$ & $13,80 \pm 0,65$ \\
\hline $\mathrm{RVC}(C Y)$ & $55,81 \pm 0,51$ & $55,61 \pm 0,47$ & $55,82 \pm 0,20$ \\
\hline $\mathrm{RCC}(C C Y)$ & $46,39 \pm 0,51$ & $46,04 \pm 0,48$ & $46,23 \pm 0,34$ \\
\hline
\end{tabular}
plus supplement

Médias não diferem $(P<0,05)$ pelo teste Tukey. Means do not differ $(P<0.05)$ by Tukey test. 
Tabela 3 - Médias e erros-padrão para condição corporal (CC), índice de compacidade da carcaça (ICC) e da perna (ICP) e idade de abate (IA) de cordeiras $1 / 2$ Dorset Santa Inês terminadas em confinamento ou em pastagem + suplementação

Table 3 - $\quad$ Means and standard errors for body condition score (BCS), carcass compactness index (CCl), hindlimb compactness index $(\mathrm{HCl})$ and slaughter age (SA) of $1 / 2$ Dorset Santa Inês lambs finished at feedlot or at pasture plus supplement

\begin{tabular}{lccc}
\hline \multirow{2}{\text{Item}}{$\begin{array}{l}\text { Sistema de terminação } \\
\text { Feeding system }\end{array}$} \\
\cline { 2 - 4 } & $\begin{array}{c}\text { Confinamento } \\
\text { Feedlot }\end{array}$ & $\begin{array}{c}\text { Pastagem }+ \\
\text { suplementação } \\
\text { Pasture plus supplement }\end{array}$ & $\begin{array}{c}\text { Média total } \\
\text { Mean }\end{array}$ \\
\hline CC (BCS) & $3,03 \pm 0,06$ & $2,96 \pm 0,06$ & $3,09 \pm 0,60$ \\
ICC (CCI) & $0,21 \pm 0,01$ & $0,20 \pm 0,01$ & $0,21 \pm 0,27$ \\
ICP (HCI) & $0,43 \pm 0,01$ & $0,44 \pm 0,01$ & $0,43 \pm 0,17$ \\
IA (SA) & $148,55 \pm 4,06$ & $149 \pm 3,75$ & $150,20 \pm 0,68$ \\
\hline
\end{tabular}

Médias não diferem $(P<0,05)$ pelo teste Tukey.

Means do not differ $(P<0.05)$ by Tukey test.

respectivamente). Valores superiores aos observados neste experimento foram relatados por Tonetto et al. (2004), em pesquisa realizada com cruzamento Ile de France x Texel, raças especializadas para corte; nesse estudo, os cordeiros machos foram terminados em pastagem natural com suplementação de $2 \%$ do $\mathrm{PV}$ e em pastagem cultivada de azevém e abatidos com peso corporal médio de $30 \mathrm{~kg}$, enquanto as fêmeas terminadas em confinamento foram abatidas com peso corporal médio de $26 \mathrm{~kg}$. Esses autores obtiveram 15,$73 ; 16,81$ e $11,68 \mathrm{~kg}$ para PCQ e 15,$37 ; 16,45$ e 11,33 para $\mathrm{PCF}$, respectivamente, provavelmente por terem utilizado raça materna especializada para corte, enquanto neste estudo utilizou-se como raça materna a Santa Inês, que possui boa habilidade materna, mas não é especializada para corte. Vasconcelos et al. (2002) trabalharam com cordeiros sem raça definida terminados em pastagem com diferentes taxas de lotação (40 e 60 animais/ha) e encontraram 11,2 e 10,3 kg para PCQ e 10,4 e 9,5 kg para PCF, respectivamente. Zundt et al. (2006), ao terminarem cordeiros Santa Inês em confinamento, encontraram média de $14,90 \mathrm{~kg}$ para PCQ e 14,51 kg para PCF, superiores à obtida neste experimento.

Os valores de PCQ e PCF neste experimento podem ser considerados satisfatórios, visto que a raça materna não é especializada para produção de carne e não está dentro da faixa de preferência da maioria dos consumidores brasileiros.

Os rendimentos verdadeiro e comercial foram superiores aos resultados médios descritos por Vasconcelos et al. (2002), que encontraram para RC e RV taxas de lotação de 40 e 60 animais/ha $(42,8 ; 39,4 ; 39,8$ e $36,2 \%$, respectivamente), provavelmente porque as fêmeas apresentaram melhor rendimento que os machos inteiros, o que pode ser explicado por sua maior precocidade. Oliveira et al. (2002), em experimento realizado com cordeiros machos inteiros das raças Santa Inês e Bergamácia, com média de 135 dias de idade e peso corporal médio de $30 \mathrm{~kg}$ recebendo $80 \%$ de concentrado ( $25 \%$ de dejetos de suíno) e $20 \%$ de volumoso, encontraram média de $53,2 \%$ para rendimento de carcaça, que foram inferiores aos obtidos por Zundt et al. (2006), de 56,51 e 49,79\% para RV e RC, respectivamente, superiores aos obtidos neste experimento. Segundo Sañudo \& Sierra (1986), os rendimentos de carcaça variam de 40 a $60 \%$, de acordo com a raça, os cruzamentos e o sistema de criação. Logo, os dados desta pesquisa são compatíveis com os desses autores.

$\mathrm{Na}$ Tabela 3 encontram-se as variáveis relacionadas ao desenvolvimento muscular das cordeiras.

Os valores médios para condição corporal das cordeiras terminadas em PS e CT foram superiores aos encontrados por Yamamoto et al. (2005), em estudo com cordeiros Santa Inês, e Zundt et al. (2006), também com Santa Inês em confinamento $(2,70)$, e inferiores aos verificados por Zundt et al. (2003), ao avaliarem cordeiros "tricoss" $1 / 2$ Texel + 1/4 Bergamácia $+1 / 4$ Corriedale terminados em confinamento. Segundo esses autores, a CC encontrada caracteriza a carcaça da raça Santa Inês como de menor musculosidade em comparação às de raças já definidas para corte. Portanto, os dados encontrados neste experimento estão de acordo com a literatura.

Os valores obtidos para ICC corroboram os descritos por Reis et al. (2001), de $0,21 \mathrm{~kg} / \mathrm{cm}$, porém, o ICP foi superior ao obtido por esses autores. Segundo Osório (1992), as carcaças mais pesadas apresentam maior índice de compacidade e as de melhor conformação são mais curtas. Carvalho et al. (2002), estudando características de carcaça de cordeiros Santa Inês, encontraram valores médios de ICC de $0,20 \mathrm{~kg} / \mathrm{cm}$ para cordeiros abatidos com $25 \mathrm{~kg}$ de peso corporal e $0,28 \mathrm{~kg} / \mathrm{cm}$ para cordeiros abatidos com $35 \mathrm{~kg}$. Alves et al. (2003), trabalhando também com cordeiros Santa Inês, encontraram resultados médios de $0,26 \mathrm{~kg} / \mathrm{cm}$ para ICC e 0,35 para IPC. Zundt et al. (2003) encontraram $0,27 \mathrm{~kg} / \mathrm{cm}$ para ICC e $0,43 \mathrm{ICP}$, semelhantes aos valores verificados neste estudo. Zundt et al. (2006), por sua vez, obtiveram $0,24 \mathrm{~kg} / \mathrm{cm}$ para ICC e 0,40 para ICP, superiores aos valores médios obtidos para ICC e inferiores aos resultados referentes a ICP quando comparados aos deste experimento.

Santos et al. (2002) abateram cordeiros Santa Inês puros com 28 a $30 \mathrm{~kg}$ de PV e média de 162 dias de idade e Yamamoto et al. (2005) observaram idade de abate dos cordeiros Santa Inês de 158 dias e de 124 dias para os mestiços Dorset x Santa Inês. As idades de abate encon- 
tradas neste experimento foram semelhantes às obtidas por esses autores, para cordeiros Santa Inês. são semelhantes às obtidas. Entretanto, Yamamoto et al. (2005) encontraram idade de abate inferior para cordeiros $1 / 2$ Dorset Santa Inês, como esperado no referido experimento.

Os animais terminados em pastagem + suplementação não tiveram nenhum problema decorrente de verminose, provavelmente em virtude do manejo adotado: eram recolhidos no período noturno em instalações cobertas (piso ripado e suspenso) e soltos na pastagem após a secagem do orvalho, com método de pastejo intermitente (Silva Sobrinho, 2001).

De acordo com a análise econômica da produção de carne de cordeiras (Tabela 4), a diferença (renda líquida operacional do sistema pastagem + suplementação subtraída da renda líquida operacional do confinamento) favorável ao sistema de terminação de pastagem + suplementação ( $\mathrm{R} \$ 602,01)$ pode ser atribuída ao custo total da ração consumida pelos animais do confinamento, haja vista o custo mais elevado do quilo do suplemento.
Neste experimento, nenhum dos sistemas de terminação teve receita líquida negativa, porém, o ganho corporal médio diário dos animais do confinamento não foi o esperado. O ganho de peso no confinamento (abaixo de $0,200 \mathrm{~kg} / \mathrm{dia}$ ) contraria a recomendação de Siqueira (2000) de que este é o ganho mínimo econômico para terminação de cordeiros em confinamento. Os baixos ganhos de peso observados nos dois sistemas não têm explicação biológica, pois foram utilizados animais cruzados e a ração fornecida foi formulada para suprir as necessidades para esse ganho mínimo esperado. Porém, como foram utilizadas apenas com fêmeas, o ganho corporal médio diário foi menor do esperado, pois animais machos, por sua fisiologia, possuem velocidade de crescimento superior à das fêmeas.

O custo de produção do quilograma de carcaça produzido neste experimento foi superior aos obtidos por Macedo et al. (2000), em sistema de terminação em pastagem e confinamento (R \$2,26 e R \$2,31), e Macedo (1995), trabalhando com resíduo de destilaria de álcool. Porém, esse

Tabela 4 - Análise econômica da produção de carne de cordeiras em confinamento ou em pastagem + suplementação (módulo de 100 cordeiras por sistema)

Table 4 - Economical analysis of lamb meat production at feedlot or at pasture plus supplement (100 lambs per system)

\begin{tabular}{|c|c|c|}
\hline $\begin{array}{l}\text { Variável } \\
\text { Item }\end{array}$ & $\begin{array}{c}\text { Confinamento } \\
\text { Feedlot }\end{array}$ & $\begin{array}{c}\text { Pastagem }+ \text { suplementação } \\
\text { Pasture plus supplement }\end{array}$ \\
\hline Peso vivo inicial $(\mathrm{kg})$ (Initial body weight, $\mathrm{kg}$ ) & $20,58 \pm 0,39$ & $20,11 \pm 0,38$ \\
\hline Ganho de peso médio diário $(\mathrm{kg})$ (Average daily weight gain, $\mathrm{kg}$ ) & $0,157 \pm 0,01$ & $0,148 \pm 0,23$ \\
\hline Dias em terminação (Days on fattening) & $65,59 \pm 3,66$ & $65,46 \pm 3,38$ \\
\hline Rendimento comercial da carcaça (\%) (Commercial carcass yield, \%) & $46,39 \pm 0,50$ & $46,04 \pm 0,47$ \\
\hline Peso da carcaça fria $(\mathrm{kg})$ (Cold carcass weight, $\mathrm{kg}$ ) & $13,91 \pm 0,25$ & $13,67 \pm 0,23$ \\
\hline $\mathrm{N}^{0}$ animais abatidos (N. of slaughtered animals) & 100 & 100 \\
\hline Carcaça total $(\mathrm{kg})$ (Total carcass weight, $\mathrm{kg}$ ) & 1.391 & 1.367 \\
\hline Receita total $(\mathrm{R} \$ 9,50 / \mathrm{kg})$ (Total income, $R \$ 9.50 / \mathrm{kg}$ ) & $13.214,50$ & $12.986,50$ \\
\hline
\end{tabular}

Despesas

Expenses

Arrendamento* (R\$40,00/ha/mês) (Renting*, R\$40.0/ha/month)

Instalações $\left(50 \mathrm{~m}^{2}\right)$ (Buildings, $50 \mathrm{~m}^{2}$ )

Amortização 10 anos ( $\$ \$ 500,00)$ (10-year amortization, $R \$ 500,00)$

Compra de animais (R\$76,00/animal) (Animal purchase, R\$76,00/animal)

Alimentação (kg-ração) (Feeding, kg-ration)

Consumo ração/animal/dia (kg) (Concentrate intake/animal/day, $\mathrm{kg}$ )

Consumo ração/animal/terminação ( $\mathrm{kg}$ ) (Concentrate intake/animal/finishing)

Valor da alimentação (R\$) (Feed costs, $R \$$ )

Vermífugo (Vermifuge)

Minerais ( $\mathrm{R} \$)$ (Minerals)

Mão-de-obra (R\$) - (Diária: R\$ 15,00) (Labor, R\$)

Despesa total (R\$) (Total expenses, $R \$$ )

Custo operacional total por carcaça (R\$) (Total operational total per carcass, R\$)

Custo operacional por $\mathrm{kg}$ de carcaça $(\mathrm{R} \$$ ) (Operational cost per carcass $\mathrm{kg}, R \$$ )

Renda líquida operacional (R\$) (Net operational income, R\$)

Diferença (R\$): (suplementação - confinamento) (Difference [R\$]: (supplement - feedlot)
480,00 (4 ha- 90 dias)

$5.000,00$

$90,40(66$ dias $)$

$7.600,00$

$2.568,06$

0,382

13,87

$1.386,75$

$10,80(200 \mathrm{~mL})$

$95,04(79,2 \mathrm{~kg})$

66 dias $\times 1 \mathrm{~h} / \mathrm{dia}=123,75$

66 dias $\times 1 \mathrm{~h} / \mathrm{dia}=123,75$

$9.775,95$

97,75

7,15

$3.210,55$

$+602,01$ 
autor não considerou o arrendamento da terra nem os custos com as instalações das cordeiras durante todo o período de terminação. Zundt et al. (2002) obtiveram custo médio do quilograma da carcaça de cordeiros terminados em confinamento de $\mathrm{R} \$ 2,53$, sendo as carcaças comercializadas a $\mathrm{R} \$ 4,50 / \mathrm{kg}$. Os resultados econômicos encontrados neste experimento foram superiores aos obtidos por Vasconcelos et al. (2002), em estudo com cordeiros sem raça definida em pastagem nativa e capim-tanzânia com carga variável de 40 e 60 animais/ha abatidos com 25 a $26 \mathrm{~kg}$ de peso corporal (lucro médio por kg/carcaça de $\mathrm{R} \$ 0,07$ e $\mathrm{R} \$ 0,21$, respectivamente).

Verificou-se também renda líquida superior para cordeiras terminadas em pastagem + suplementação $(\mathrm{R} \$ 3.210,55)$ em relação às do confinamento $(\mathrm{R} \$ 2.608,54)$. Macedo et al. (2000), terminando cordeiros em confinamento ou em pastagem de coastcross, encontrou diferença de $\mathrm{R} \$ 275,13$ para renda líquida em favor dos animais terminados em confinamento. Siqueira et al. (2001), em experimento com fêmeas em confinamento abatidas com 28 e $32 \mathrm{~kg}$, encontraram renda líquida de $\mathrm{R} \$ 12,56$ e $\mathrm{R} \$ 8,47$ por cordeiro, respectivamente, inferior à deste experimento.

\section{Conclusões}

Considerando as características idade de abate, condição corporal, pesos de carcaça quente e de carcaça fria, rendimentos verdadeiro e comercial da carcaça e índices de compacidade da carcaça e da perna, cordeiras $1 / 2$ Dorset Santa Inês podem ser terminadas em sistemas de confinamento ou em pastagem + suplementação. Porém, pela análise de custos, recomenda-se a terminação das cordeiras em sistema de pastagem + suplementação.

\section{Literatura Citada}

ALVES, K.S; CARVALHO, F.F.R.; FERREIRA, M.A. et al. Níveis de energia em dietas para ovinos Santa Inês: características de carcaça e constituintes corporais. Revista Brasileira de Zootecnia, v.32, n.6, p.1927-1936, 2003 (supl.2).

BUENO, M.S.; CUNHA E.A.; SANTOS, L.E. Santa Inês sheep breed in the intensive lamb meat production in the southeast region of Brazil. In: GLOBAL CONFERENCE ON CONSERVATION OF DOMESTIC ANIMAL RESOURCES, 5., 2000, Brasília. Proceedings... Brasília: EMBRAPA, 2000. (CD-ROM)

CARVALHO, P.A.; PÉREZ, J.R.; GERASEEV, L.C. et al. Características quantitativas da carcaça de cordeiros Santa Inês submetidos a diferentes manejos alimentares. In: REUNIÃO ANUAL DA SOCIEDADE BRASILEIRA DE ZOOTECNIA, 39, 2002. Recife. Anais... Recife: Sociedade Brasileira de Zootecnia, 2002 (CD ROM).

CORREAA, A.R. Forrageiras: aptidão climática do estado do Paraná. In: MONTEIRO A.L.G.; MORAES, A.; CORRÊA, E.A.S. et al. (Eds.) Forragicultura do Paraná. Londrina: CPAF, 1996. p.75-92.
CUNHA, E.A.; BUENO, M.S.; SANTOS L.E. et al. Sistema intensivo de produção ovina. Nova Odessa: Instituto de Zootecnia, 2001. 51p. (apostila).

CUNHA, E.A.; BUENO, M.S.; SANTOS, L.E. Características de carcaças de cordeiros de raças de corte criados intensivamente. Disponível em: http://www.cico.rj.gov.br Acesso em: 23/12/2002.

MACEDO, F.A.F. Resíduos de destilaria de álcool na terminação de cordeiros em confinamento. In: REUNIÃO ANUAL DA SOCIEDADE BRASILEIRA DE ZOOTECNIA, 32., 1995, Brasília. Anais... Brasília: Sociedade Brasileira de Zootecnia, 1995. p.169-71.

MACEDO, A.F.M.; SIQUEIRA, E.R.; MARTINS, N.E. Análise econômica da produção de carne de cordeiros sob dois sistemas de terminação: pastagem e confinamento. Ciência Rural, v. 30, n. 4, p. $677-680,2000$

NATIONAL RESEARCH COUNCIL - NRC. Nutrients requirements of sheep. 5.ed. Washington, D.C.: National Academy Press, 1985. 99p.

OLIVEIRA, M.V.M.; PÉREZ, J.R.O.; ALVES, E.L. et al. Rendimento de carcaça, mensurações e peso de cortes comerciais de cordeiros Santa Inês e Bergamácia alimentados com dejetos de suínos em confinamento. Revista Brasileira de Zootecnia, v.31, n.3, p.1451-1458, 2002 .

OSÓRIO, J.C.S. Estudio de la calidad de canales comercializadas en el tipo ternasco segun la procedencia: bases para la mejora de dicha calidad en Brazil. Zaragoza: Universidad de Zaragoza. 1992. 335p. Tese (Doctorado) Universidad de Zaragoza, 1992.

REIS, W.; JOBIM, C.C.; MACEDO, F.A.F. et al. Características da carcaça de cordeiros alimentados com dietas contendo grãos de milho conservado em diferentes formas. Revista Brasileira de Zootecnia, v.30, n.4, p.1308-1315, 2001.

RUSSEL, A.J.F.; DONEY, J.M.; GUNN,R.G. Subjective assessment of body fat in live sheep. Journal Agricultural Science, v.72, p.451-454, 1969 .

SANTOS, L.E.; BUENO, M.S.; CUNHA, E.A. et al. [2002]. Desempenho e característica de carcaça de cordeiros Santa Inês e cruzados com raças especializadas para corte 1. Trabalhos técnicos. Disponível em: http:// www.ovinosbrasil.com/trab_tec/pg_trab_tecs_017.htm Acesso em: $15 / 12 / 2002$

SAÑUDO, C.; SIERRA, I. Calidad de la canal en la especie ovina. Ovino, n.1, p.127-57, 1986.

STATISTICAL ANALYSIS SYSTEM - SAS. SAS Technical Report. Release 6.07. Cary: 1992. 229p.

SILVA SOBRINHO, A.G. Produção de ovinos em regime de pasto. In: SILVA SOBRINHO, A.G. (Ed.) 2.ed. rev. Criação de ovinos. Jaboticabal: Funep, 2001. p.21-49.

SIQUEIRA, E.R. Sistemas de confinamento de ovinos para corte do Sudeste do Brasil. In: SIMPÓSIO INTERNACIONAL SOBRE CAPRINOS E OVINOS DE CORTE, 1., 2000, João Pessoa. Anais... João Pessoa: Empresa Estadual de Pesquisa Agropecuária da Paraíba/AS, 2000. p.107-117.

SIQUEIRA, E.R; SIMÕES, C.D.; FERNANDES, S. Efeito do sexo e do peso ao abate sobre a produção de carne de cordeiro. I. Velocidade de crescimento, caracteres quantitativos da carcaça, $\mathrm{pH}$ da carne e resultado econômico. Revista Brasileira de Zootecnia, v.30, n.3, p.844-848, 2001

SOUSA, O.C.R. Rendimento de carcaças, composição regional e física da paleta e quarto em cordeiros Romney Marsh abatidos aos 90 e 180 dias de idade. Pelotas: Universidade Estadual de Pelotas, 1993. 103p. Dissertação (Mestrado em Zootecnia) - Universidade Estadual de Pelotas, 1993.

TONETTO, C.J.; PIRES, C.; MÜLLER, L. et al. Ganho de peso e características da carcaça de cordeiros terminados em pastagem natural suplementada, pastagem cultivada de azevém (Lolium multiflorum Lam.) e confinamento. Revista Brasileira de Zootecnia, v.33, n.1, p.225-233, 2004. 
VASCONCELOS, V.R.; SOUSA, F.B.; BARROS, N.N. et al. Rendimento de carcaça e peso de cortes comerciais de cordeiros terminados a pasto. In: REUNIAO ANUAL DA SOCIEDADE BRASILEIRA DE ZOOTECNIA, 39., 2002, Recife. Anais... Recife: Sociedade Brasileira de Zootecnia, 2002. (CD-ROM). Nutrição de Ruminantes. SBZ879.

WILM, H.G.; COSTELO, O.F.; KLIPPLE, G.E. Estimating forage yild by the double sampling method. Jornal American of Agronomic, v.36, n.1, p.194-203,1944.

YAMAMOTO, S.M.; MACEDO, F.A.F.; ZUNDT, M. et al. Fontes de óleo vegetal na dieta de cordeiros em confinamento. Revista Brasileira de Zootecnia, v.34, n.2, p.703-710, 2005.

ZUNDT, M.; MACEDO, F.A.F.; ASTOLPHI, J.L.L. et al. Desempenho e características de carcaça de cordeiros Santa Inês confinados, filhos de ovelhas submetidas à suplementação alimentar durante a gestação. Revista Brasileira de Zootecnia, v.35, n.3, p.928-935, 2006.
ZUNDT, M.; MACEDO, F.A.F.; MARTINS, E.N. et al. Desempenho de cordeiros alimentados com diferentes níveis protéicos. Revista Brasileira de Zootecnia, v.31, n.3, p.1307-1314, 2002.

ZUNDT, M.; MACEDO, F.A.F.; MARTINS, E.N. et al. Características de carcaça de cordeiros terminados em confinamento, com dietas contendo diferentes níveis protéicos. Ciência Rural, v.33, n.3, p.565-571, 2003.

Recebido: 01/08/05 Aprovado: 04/04/06 